\title{
The Performance Evaluation of a Cassava Pelletizer
}

\author{
${ }^{1}$ O. B. Oduntan, ${ }^{2}$ O. A. Koya, ${ }^{3}$ M. O. Faborode, ${ }^{4}$ A. O. Oduntan \\ ${ }^{1}$ Department of Agricultural and Environmental Engineering, University of Ibadan, Ibadan Nigeria. \\ ${ }^{2}$ Department of Mechanical Engineering, Obafemi Awolowo University, Ile-Ife 22005, Nigeria. \\ ${ }^{3}$ Department of Agricultural Engineering, Obafemi Awolowo University,Ile-Ife 22005.Nigeria. \\ 4National Horticultural Research Institute, P.M.B.5432, Idi-Ishin Ibadan Nigeria
}

\begin{abstract}
This paper reports on the performance evaluation of a machine for cottage level production of pellets from cassava mash. Peeling, grating and drying freshly harvested cassava tubers, produced cassava flour. The flour was mixed with water at different blend ratios to form cassava mash of different moisture contents. The performance of the pelletizer was evaluated in terms of the density, durability, crushing strength and cyanide content of the pellets, and the throughput of the machine, against the moisture content of the mash 18,20 and $22 \%$ w.b.), die size (4, 6 and $8 \mathrm{~mm}$ ) and the auger speed (90, 100 and $120 \mathrm{rpm})$. Test results showed that the bulk density and the durability of pellets decreased while the moisture content increased significantly $(p<0.05)$ and separately with increasing die size and moisture content of cassava mash. The pellets with the best quality attributes were obtained from cassava mash at 18\% moisture content (w.b.) through the $4 \mathrm{~mm}$ die at $90 \mathrm{rpm}$ and a maximum throughput of $54 \mathrm{~kg} / \mathrm{hr}$. The machine, thus, provides a significant leverage in the utilization of cassava as pelletized animal feed.
\end{abstract}

Key Words: Density, die, durability, pelletizer, throughput.

\section{Introduction}

Global production of cassava tubers and the post-harvest processing activities have been on the increase in the last 20 years. The products from cassava tuber are prepared for human and animal consumption and industrial use, but with growing emphasis on animal consumption and industrial uses. Until recently, about $85 \%$ of the world production of cassava was consumed by man. The remaining $15 \%$ was shared between animal and chemical industries [1].

However, the tuber is best administered in pelletized form, when it must be fed, or compounded with other ingredients, as animal feed. Compounding cassava with other ingredients for livestock feeds has gained wide practice in Latin America, Asia and the European Union [2]. The pellets also have better keeping quality and required less storage space compared to raw tubers [3].

Over time, series of processing equipment at different levels of sophistication were imported into Nigeria for the pelletization process [4]; [5]. Major problems associated with such machines included high initial and maintenance costs, requirement for highly skilled maintenance engineering staff and dependency on expensive infrastructure facilities. On the other hand, it is arguable that local manufacture of machines is both technically and economically feasible in Nigeria [6]. In this direction, previous designs have employed complex technological processes, mimicking the imported versions [7]. Consequently, the pelletizing plant remained capital intensive and prohibitive for the class of small and medium scale investors. Therefore, the development of versions of simply designed pelletizer should be seen as technological development to satisfy a niche market in the industry. Thus, this work was conceived in the search for a simple technology to process cassava flour to pellets using locally available materials. Hence, the main objectives of this work were to design and fabricate a cassava pelletizer; and evaluate its performance.

\subsection{The Experimental Pelletizer}

\section{Performance Test}

The pelletizer (Fig. 1) is basically a combination of an auger and a die. The die serves as a back plate for retaining the pressure exerted by the auger; whilst, the perforations in the die allow the compressed mash wriggle out to form pellets. A helical auger is mounted on a tapering shaft which is supported on bearings so that the shaft rotates freely in the stationary cylindrical barrel.

Cassava mash is introduced into auger through the inlet gate of the barrel. The auger conveys the mash to the die and builds up pressure for its extrusion. Pressure resulting from rotating auger forces the mash through the perforations in the die, compressing and forming it into pellets. The pellets were allowed to break off by force of gravity, so that, sizing was random, but excessively long particles are likely to be readily broken during handling. The pelletizer consists of the following parts: the barrel, a shaft on which is welded the auger, the 
hopper, heat exchanger barrel, reduction gear and the frame. Each component was designed following standard engineering principle [8].

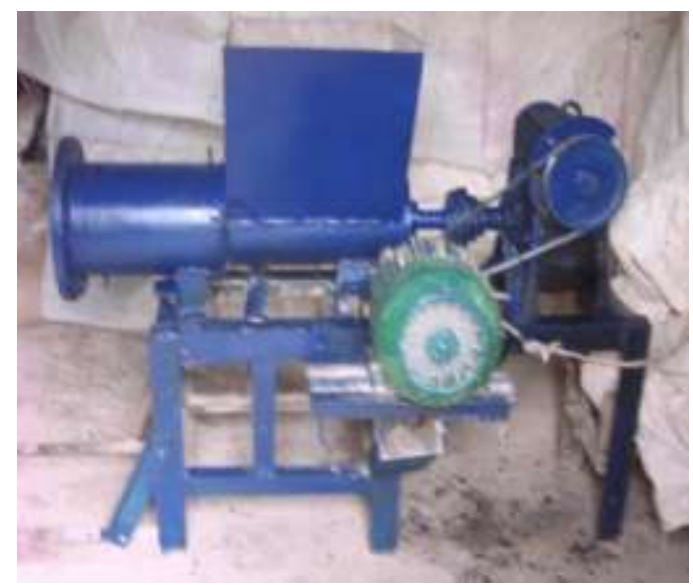

Fig 1: A picture of the experimental cassava pelletizer

\subsection{Performance Evaluation}

2.2.1 Sample preparation

Cassava tubers were obtained from a local farm in Ibadan, Nigeria. The tubers were washed, peeled with knife, grated and dried into cassava flour. The moisture content of the cassava flour at the time of the experiment was determined using the oven method [9]. Samples of the flour were conditioned by adding water at different blend ratio $(2.5,3.0$ and $3.5 \mathrm{~kg}$ of water to $10 \mathrm{~kg}$ of the flour) for 10 minute in a mixer (Fexod AS 170 , Nigeria). The samples were dried gradually at $140{ }^{\circ} \mathrm{C}$ in a heat chamber and weighed occasionally until the predetermined moisture content of 18, 20 and $22 \%$ (w.b) were obtained. Each experimental run was replicated three times.

\subsubsection{Quality assessments of the pellets}

The performance of the pelletizer was evaluated on the basis of the throughput of the machine and the quality of pellets recovered at the various shaft speeds and die sizes, for cassava mash of different initial moisture contents. Quality of the pellet was defined in terms of its durability, crushing strength, bulk density and the cyanide content.

The durability $\left(\mathrm{D}_{u}\right)$ of the pellets was determined according to ASABE S269.4 [10]. A $100 \mathrm{~g}$ sample of the pellet was tumbled at $50 \mathrm{rpm}$ for $10 \mathrm{~min}$ in a dust tight enclose (Engineering Laboratory Equipment, London). Sieves with 3,5, and $7 \mathrm{~mm}$ apertures were used respectively for the pellets extruded from the 4, 6 and $8 \mathrm{~mm}$ dies. Durability was expressed as the percent ratio of the mass of pellets retained on the sieve after tumbling $\left(\mathrm{M}_{\mathrm{pa}}\right)$ to mass of pellet before tumbling $\left(\mathrm{M}_{\mathrm{pb}}\right)$. Durability is said to be high when the measured value is above $80 \%$, medium when between 70 and $80 \%$ and low when below 70\% [7]:

$$
D_{u}=\frac{M_{p a}}{M_{p b}} \times 100 \%
$$

Bulk density of the pellet was determined as recommended by ASABE S269.4 [10]. A container was filled using a funnel, without compacting the content. The material was levelled with the top surface of the container and weighed. Pellet and flour bulk densities were obtained from the ratios of the measured masses of samples in the container to the volume of the container. Five measurements of each experimental run were taken to obtain the average values and standard deviations. Bulk density is an important parameter in the design of systems for drying, ventilation and cooling of pellets during storage [12]; [13].

The strength at rupture of the specimens of the pellet was measured in diametral compression (Lloyd instruments, model 1000R, Hampshire, UK). The compression test equipment was fitted with a $500 \mathrm{~N}$ load cell. The length of each pellet was measured with a calliper and recorded before it was positioned for compression at a rate of $10 \mathrm{~mm} / \mathrm{min}$. Thus, the force applied on the pellet increased gradually and the load at breakage was noted.

In the determination of the cyanide content, $0.1 \mathrm{~g}$ of pellet from each of the 4,6 and $8 \mathrm{~mm}$ dies was weighed into a flat-bottom plastic bottle with a screw cap lid; $0.5 \mathrm{~mL}$ of $0.1 \mathrm{M}$-phosphate buffer at $\mathrm{pH} 6$ was added with a pipette [14]. A yellow picrate paper was attached to a plastic strip in the bottle containing sample but not touching the liquid in the bottle. The bottle was immediately closed with the screw-capped lid. A blank 
was also prepared, as above, into another screw capped bottle and the difference was used in calculating the total cyanide content.

\section{Results And Discussion}

3.1 Quality Attributes of the Pellets

A summary of the quality attributes of the pellets extruded from the machine is shown in Table 1. A typical trend of the moisture content of the pellets is shown in Fig. 2. The results show that pellets extruded through the largest holes and at the highest speed are more moisture-laden than pellets from the narrow die at the least speed. This is not unusual, because running the mash against a smaller die holes generate heat and pressure in the barrel, which reduced the moisture content of the pellet. However, statistical analysis showed that only the moisture content of the

\begin{tabular}{|c|c|c|c|}
\hline Parameter & Grimum Value Maximum & ValueAverage Value & \\
\hline Pellet $M C(\%, 6)$. & 11.4 & 13.4 & $12.4(1.0)^{x}$ \\
\hline Bullk Density ( $\mathrm{kgm}^{3}$ ) & 530 & 635 & $578(53)$ \\
\hline Cyanide Content (mg kg) & 4.76 & 5.14 & $4.93(0.19)$ \\
\hline Crushing Strenght (MPa) & 8.86 & 34.24 & $18.20(1.70)$ \\
\hline Durability $(\%)$ & 59.3 & 85.7 & $73.8(8.0)$ \\
\hline Nachine Throughput (kghr) & 25.2 & 67.2 & $55.0(6.9)$ \\
\hline
\end{tabular}

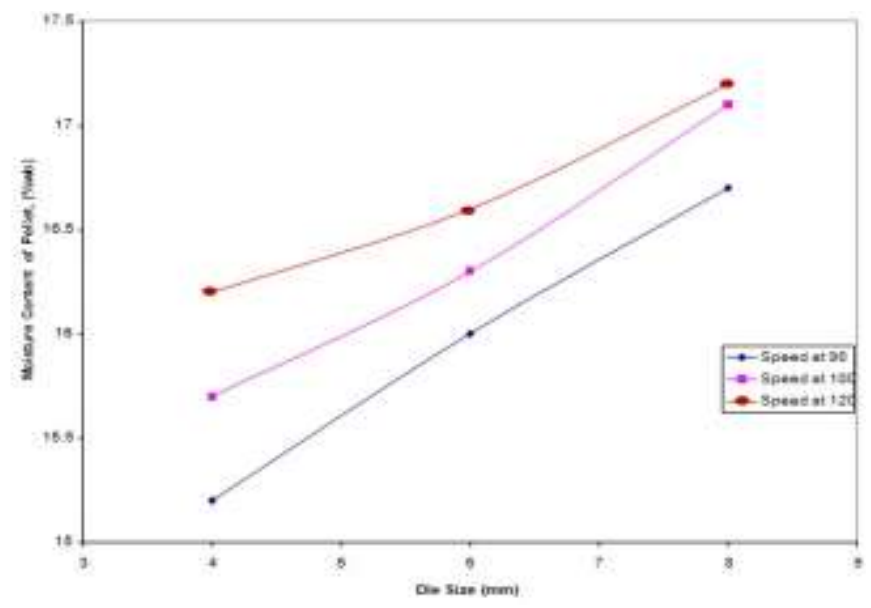

Fig. 2: Effect of die size on the moisture content of the pellet from cassava mash at $18 \%$ moisture content (w.b.) pelletized at various speeds.

mash and die size had significant effects on the moisture content of the pellets, but the effect of the speed of the pelletizer was not significant (Table 2).

Table 2: Summary of ANOVA on the effects of Speed, MC and Die on MC of pellets

\begin{tabular}{|c|c|c|c|c|}
\hline \multirow{3}{*}{$\begin{array}{l}\text { Source of Variation } \\
\text { Die Size } \\
\text { Speed }\end{array}$} & \multicolumn{2}{|c|}{ Deg. of Freedom Sum of Sq. } & \multicolumn{2}{|c|}{ F-Value Variation } \\
\hline & 2 & 22.1165432 & 27.71 & $<.0011^{\circ}$ \\
\hline & 2 & 0.2639506 & 0.33 & 0.7199 \\
\hline Moisture Content & 2 & 183.3380247 & 229.67 & $<0001^{\circ}$ \\
\hline Die*Speed & 4 & 1.0064198 & 0.63 & 0.6429 \\
\hline Die*MC & 4 & 2.4123457 & 1.51 & 0.2120 \\
\hline Speed*MC & 4 & 3.2427160 & 2.03 & 0.1030 \\
\hline Speed*Die* MC & 8 & 0.5964198 & 1.49 & 0.1811 \\
\hline
\end{tabular}

${ }^{{ }^{*}}$ Siguificant at $95 \%$ confidencelevel. 


\subsection{Effects of Machine Parameters on Product Quality}

Performance evaluation of the machine showed that bulk density of the pellets decreased with higher diameter of the die through which the pellets were extruded, indicating that the bigger pellets are more loosely packed, providing more voids to facilitate air flow for ventilation and drying, but requiring more space for handling and transportation.

Similarly, the crushing strength and the durability of the pellets decreased with the die size, showing that the bigger pellets will crumble more readily during handling than the smaller ones. Maximum durability of $84 \%$ was recorded at $20 \%$ (w.b.) moisture content using $4 \mathrm{~mm}$ die, while the least was $62 \%$ using the $8 \mathrm{~mm}$ die. It is likely that the binding forces in small size pellets have strengthened the bond between individual particles in the pellet. Furthermore, the higher quantity of heat generated in the barrel due to the stricter frictional resistance, due to the small hole size $(4 \mathrm{~mm})$ must have enhanced starch gelatinization in the pellet, thus, binding the particles together more firmly. A typical curve of variation of pellets' durability with die size at the different auger speeds is shown in Fig. 3. Statistical analysis showed that only the die size has significant effect on pellet durability.

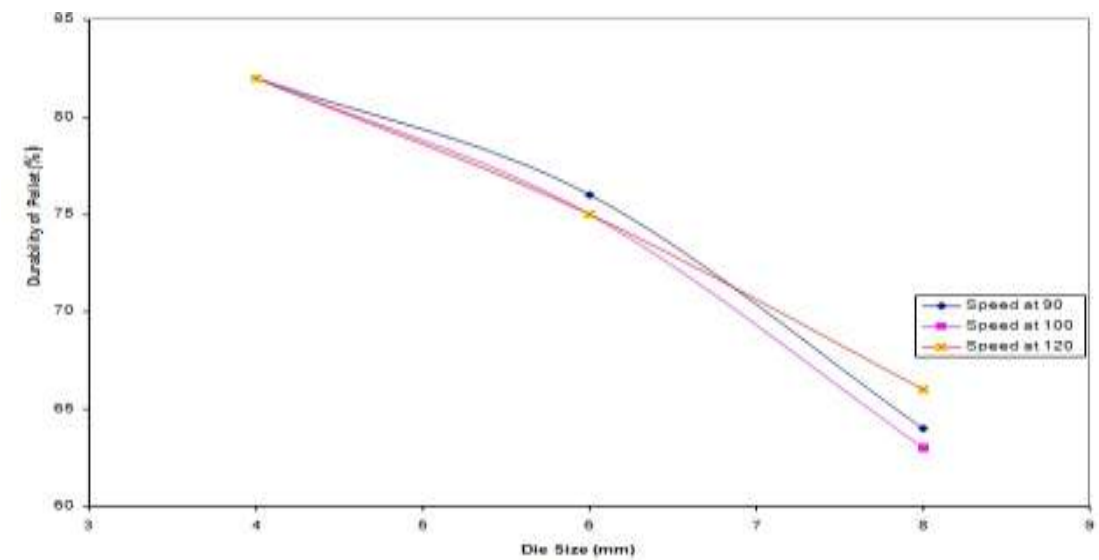

Fig. 3: Effect of die size on the durability of the pellets at $18 \%$ MC pelletized at various speeds and die sizes.

A summary of the effects of the moisture content of the mash and the operational parameters of the machine on the quality of the pellets is shown in Table 3. The corresponding throughput capacities of the machine are also shown in the table.

TABLE 3: Summary of Duncan's multiple range tests on main effects (speed, moisture content and die) on pellets moisture content, durability and machine throughput

\begin{tabular}{|c|c|c|c|c|}
\hline \multicolumn{2}{|c|}{ Variable } & $\mathrm{MC}(\%)$ & Durability (\%) & Throughput (kg/hr) \\
\hline \multirow[t]{3}{*}{ Speed } & 90 & $18.11^{\mathrm{a}}$ & $73.84^{\mathrm{a}}$ & $51.7^{\mathrm{a}}$ \\
\hline & 100 & $18.16^{\mathrm{a}}$ & $73.36^{\mathrm{a}}$ & $54.4^{\mathrm{b}}$ \\
\hline & 120 & $18.25^{\mathrm{a}}$ & $74.11^{\mathrm{a}}$ & $50.4^{\mathrm{b}}$ \\
\hline \multirow[t]{3}{*}{$\mathrm{MC}$} & 18 & $16.32^{\mathrm{a}}$ & $74.30^{\mathrm{a}}$ & $53.5^{\mathrm{a}}$ \\
\hline & 20 & $18.17^{\mathrm{b}}$ & $73.81^{\mathrm{a}}$ & $59.2^{\mathrm{b}}$ \\
\hline & 22 & $20.02^{\mathrm{c}}$ & $73.76^{\mathrm{a}}$ & $52.4^{\mathrm{b}}$ \\
\hline \multirow[t]{3}{*}{ Die } & 4 & $17.49^{\mathrm{a}}$ & $81.87^{\mathrm{a}}$ & $53.7^{\mathrm{b}}$ \\
\hline & 6 & $18.28^{\mathrm{b}}$ & $75.79^{\mathrm{b}}$ & $53.6^{\mathrm{b}}$ \\
\hline & 8 & $18.75^{\mathrm{c}}$ & $63.66^{\mathrm{c}}$ & $57.7^{\mathrm{a}}$ \\
\hline
\end{tabular}

Values with the same superscript in the same column are not significantly different at $\mathrm{p}<0.05$.

\section{Conclusions}

Simple, but viable machinery for converting cassava mash to highly durable pellets was developed. Feeding cassava mash with initial moisture content in the range 18 to $22 \%$ (w.b.) yielded pellets with $11-13 \%$ (w.b.), moisture content; 530-635 kg/m $\mathrm{m}^{3}$, bulk density; 8.86-34.24 MPa, crushing strength; and 59.3-85.7\%, durability, $25.2-67.2 \mathrm{~kg} / \mathrm{hr}$ throughput capacity. The work shows that only the moisture content of the mash and die size have significant effects on the moisture content of pellets. Furthermore, the bulk density, crushing strength and durability of the pellets decreased with higher diameter of the die. 


\section{References}

[1]. Adeeko, K. A. and Ajibola, O. O, Processing factors affecting yield and quality of mechanically expressed groundnut oil, Journal of Agricultural Engineering Research, 45, 1990, 31-43.

[2]. Ashaye O. A., Couple A. A., Fasoyiro S. B. and Adeniji A, Effect of Location and Storage Environment on the Quality Attributes of Gari in South-Western Nigeria, World Journal of Agricultural Sciences 1(1) 2005, 52-55.

[3]. Hrishi, N. Problems and prospects of cassava production in India. Cassava Processing and Storage. In: Proceedings of an interdisciplinary workshop, Thailand, Int. Develop. Res. Centre IDRC-031e 1974 pp.59-62.

[4]. Prestlokken, E, Protein value of expander-treated barley and oats or ruminants, Agricultural University of Norway, Doctor Scientiarum Thesis 1999:5,142pp, 1999

[5]. Pabis, S., Jayas, D. S, Grain drying Theory and Practice (John Wiley, New York, 1998)

[6]. Odigboh, E. U, Mechanization of cassava production and processing: A decade of design and development, University of Nigeria Inaugural Lecture, Series No.8, 1985.

[7]. Kwatai, J. T, Rural Cassava Processing and Utilization Centre UNICEF/IITA Collaborative Program for Household Food Security ( Lidato Press, Ibadan, 1986)

[8]. Oduntan, O. B, Development of a cassava pelletizer. Unpublished M.Sc. Thesis. Obafemi Awolowo University, Ile-Ife, Nigeria, 2010.

[9]. American Society for Testing and Materials (ASTM), Standard practice for reporting uniaxial strength data and estimating Weibull distribution parameters for advanced ceramics.(ASTM, 1995) C 1239-95: 1-18.

[10]. American Society of Agriculture and Biological Engineering (ASABE), Standard S269.4 Cubes, pellets and crumbles-definitions and methods for determining density, durability, and moisture content. (ASABE, 2003) St. Joseph, M1

[11]. Adapa. P. K., Schoenau, G. J., Tabi, L. G., Sokhansanj. S. and Crerar. B .J. (2003), Pelleting of fractionated alfalfa products. ASABE Paper No. 036069. ASABE Paper, Joseph, M1,

[12]. Fasina, O. O. and Sokhansanj, S, Modelling the bulk cooling of alfalfa pellets, Journal of Drying Tech. 13, $1995,1881-1904$.

[13]. Pipa F. and Frank, G, High-pressure conditioning with annular gap expander. A new way of feed processing: Advances in Feed Technology (2), (Verlag Moritz Schafer, Detmold, 1989).

[14]. Bradbury, M.G., Egan, S.V. and Bradbury, J.H. Determination of all forms of cyanogens in cassava roots and cassava products using picture paper kits, Journal of Science Food Agriculture, 79, 1999, 593 -601. 